\title{
THE EFFECT OF PROCESS PARAMETERS ON THICKNESS DISTRIBUTION IN THERMOFORMING
}

\author{
Olcay Ekşi ${ }^{1}$, Sencer Süreyya Karabeyoğlu²
}

1 Kırklareli University, Engineering Faculty, Mechanical Engineering Department, Kayali Campus, Kırklareli, Turkey, e-mail: olcayeksi@klu.edu.tr

2 Kırklareli University, Engineering Faculty, Mechanical Engineering Department, Kayali Campus, Kırklareli, Turkey, e-mail: sencerkarabeyoglu@klu.edu.tr

Received: 2017.04.15

Accepted: 2017.05.08

Published: 2017.06.01

\begin{abstract}
In this study, cylindrical, conical and hemispherical molds were used to form flat thermoplastic sheets which are $1.5 \mathrm{~mm}$ in thickness. The effect of plug assist on thickness distribution was investigated. The sheets were formed with and without plug assist. Then thickness distributions on thermoformed products were obtained for two experimental procedures by a digital caliper (Resolution: $0.01 \mathrm{~mm}$ ). As a result, plug assist thermoforming provides more uniform thickness distributions than negative forming.
\end{abstract}

Keywords: thermoforming, plug-assist, thickness distribution, mold.

\section{INTRODUCTION}

Thermoforming is a manufacturing process that uses heat and air pressure to form a flat plastic sheet or film in to a product. The plastic material is heated to the correct temperature depending on the kind of plastic material. Then the heated plastic sheet or film is formed in to a negative or positive mold. Plug assist may be used. Generally a vacuum or positive air pressure is employed after the forming of the plastic sheet or film. After forming, the plastic is cooled and trimmed in desired dimensions. It is possible to summarize the thermoforming process as mentioned above.

There are wide application areas of the thermoforming process. One of the most important of these sectors is the packaging industry among the other sectors such as automotive, electronics, biomedical and pharmaceuticals. Thermoforming has differences from the other competitive processes including injection molding, blow molding, rotational molding and extrusion. The most advantageous aspect of thermoforming is forming ability by roll-fed machines compared to the others. With roll-fed machines, high-volume, continuous thermoforming of thin-gauge products is possible[3, 10, 11, 12]. But, by using sheet-fed thermoforming machines, production is slow and productivity is low. Sheet-fed thermoforming machines are usually used in thick gauge thermoforming applications. So this phenomenon makes it labor intensive compared to thin gauge thermoforming applications.

Process parameters can affect both the total forming process and product quality. So, forming temperature, type of plastic (amorphous or crystalline), shape of mold (positive or negative), air pressure (positive or negative), shape, type and number of heaters play a critical role throughout the process $[4,5,7,8]$. One of the leading factors that affects the product quality is plug assist. By using plug assist in thermoforming, wall thickness distribution in thermoformed products can be adjusted more uniformly[2,6]. If a negative mold is used, the bottom of the part becomes the thinnest and if a positive mold is used the bottom of the part becomes the thickest. In order to balance the wall thickness distribution in the bottom and sidewalls of the ther- 
moformed part, plug assist thermoforming may be a quick solution. Parameters such as plug geometry, plug temperature and plug material are very critical during the forming by changing wall thickness and friction between the sheet and mold [1,9]. During the forming process, firstly the plug touches the heated sheet surface. The sheet surface generally is hotter than plug. Areas where the plug touches first, harden. Then a vacuum is applied. Softened areas of the sheet which does not harden deform and wall thickness changes through the side walls and bottom. Of course the shape of the plug is a major factor that affects the thickness distribution in products. The plug shape is determined according to product and mold shape.

In this study, aluminum is selected as a plug material. Aluminum is easy to find and suitable for machining. It is relatively cheaper than the other metals. Three different thermoforming molds have been employed. Cylindrical, conical and hemispherical molds were used to form flat thermoplastic sheets which are $1.5 \mathrm{~mm}$ in thickness. PS sheets which were cut into $15 \times 15$ cmdimensions were used in thermoforming operations. The effect of plug assist on thickness distribution was investigated. The sheets were formed with and without plug assist. Then thickness distributions on vacuum formed and plug assisted thermoformed products were obtained by a digital caliper (resolution: 0.01 $\mathrm{mm})$. Thickness profiles obtained from thermoformed products which are produced by plug assist thermoforming are different from the thickness distribution results obtained from without plug assist thermoforming. As a result, plug assist thermoforming provides more uniform thickness distributions on thermoformed products.
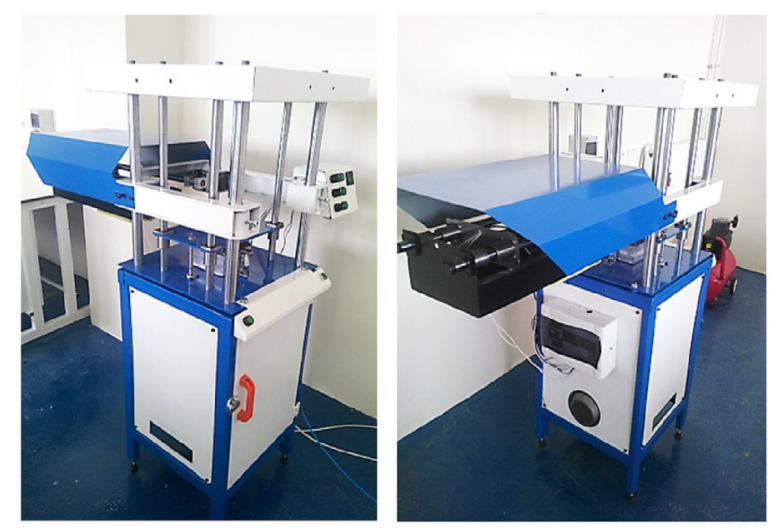

Fig. 1. Designed and final (produced) view of thermoforming machine, top to bottom respectively

\section{MATERIALS AND METHODS}

In this study, commercially available PS resin, SABIC PS 825E (High Impact Polystyrene) was used in thermoforming. Lab-scale vacuum thermoforming machine was designed, produced and used in thermoforming operations. In Fig.1. designed and final (produced) view of thermoforming machine can be seen clearly. The thermoforming machine has three ceramic infrared heaters, which are designed for operating temperatures of up to $750^{\circ} \mathrm{C}$. These heaters have a heating area of $25 \times 25 \mathrm{~cm}^{2}$. Each of the panel heaters has 500 watt power and 1500 watt in total.

Firstly, sample preparation is carried out. Thermoplastic sheets are cut to have a dimension of $15 \times 15 \mathrm{~cm}$. Sheets which have the correct dimensions are placed between the mold and the clamping ring. Then heaters are operated by bringing them to the correct position. The sheet is heated equally. PS resin, which is used in this study, has a wide forming temperature window. Forming temperature range is approximately $25-$
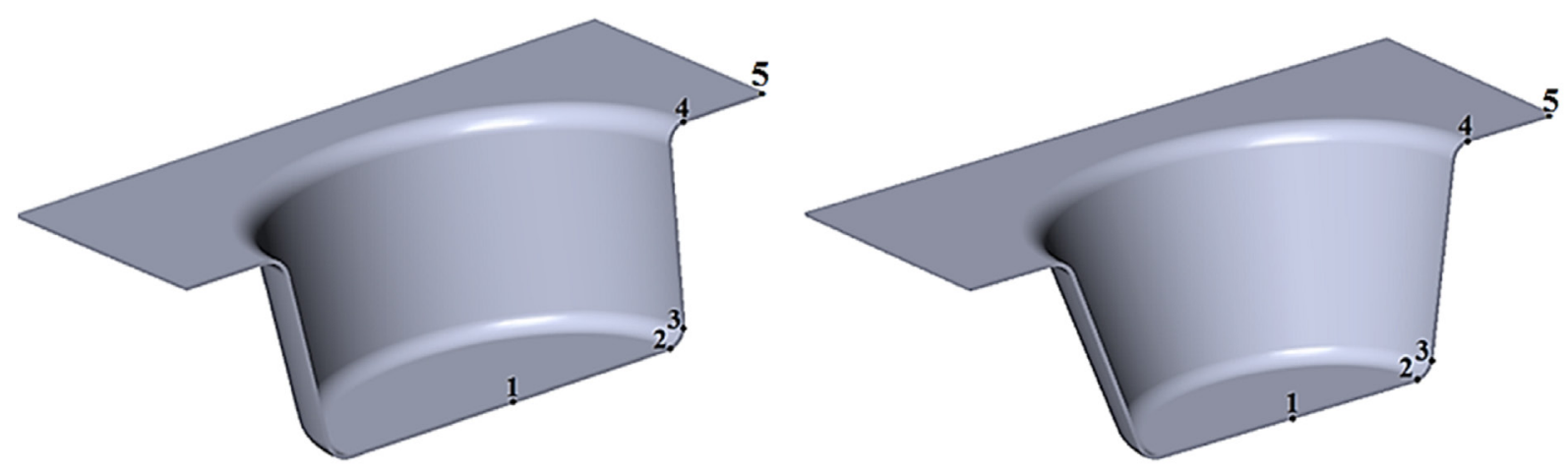

Fig. 2. Points of thickness measurement 

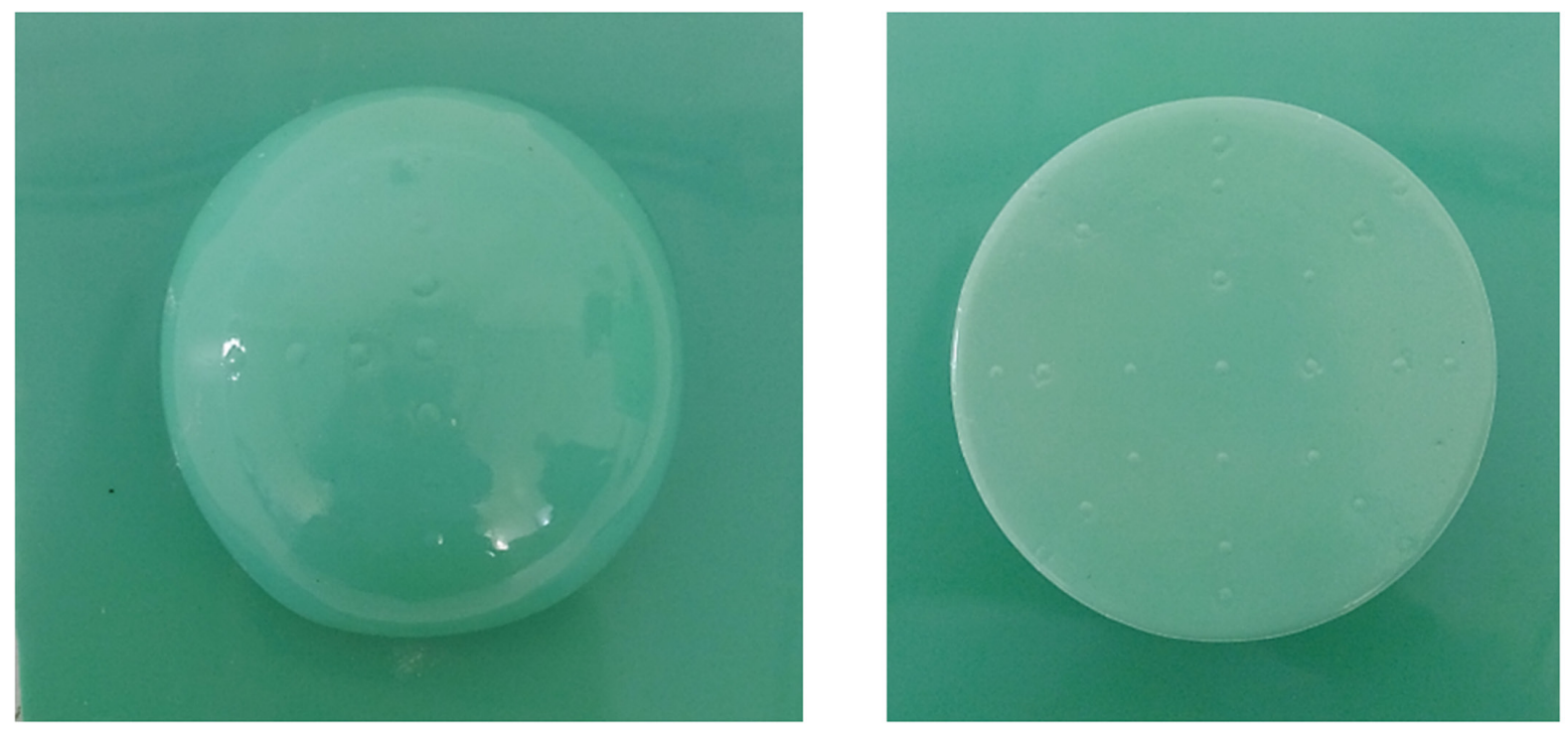

Fig. 3. Thermoformed hemispherical and cylindrical products

$30^{\circ} \mathrm{C}$. Maximum forming temperature is about $150^{\circ} \mathrm{C}$. Temperature distribution was obtained by using a thermal imaging camera (Testo). Vacuum was measured during forming. The magnitude of vacuum was obtained from the vacuum display, which was $730 \mathrm{mmHg}$. After forming, the heaters were turned off and pushed back to their first position. After a couple of minutes the thermoformed semi-finished part was released from the mold.

Three different thermoformed semi-finished samples (Fig. 3) were obtained from the thermoforming molds (Fig. 4). Quarter sections were cut and taken from conical, cylindrical and hemispherical samples. Thickness distributions were measured along the cut sections on quarter samples by a digital caliper (resolution: 0.01 $\mathrm{mm})$. These measurements were achieved for three types of thermoformed samples. Measurement operations were repeated on three samples for those which were formed by using male and female molds. Measured thickness profiles were compared to each other. The profiles in which the thicknesses were measured, is shown in Fig. 2. Thickness measurements were repeated in 20 points from point 1 to point 5 for all semi-finished thermoformed products.

\section{RESULT AND DISCUSSION}

In this study, the effect of plug assist and the other process parameters on thickness distribution has been investigated. In order to analyze the effect of process parameters, firstly temperature distribution has been detected on the heater elements. As seen in Fig. 5 and Fig. 6 heater ele-
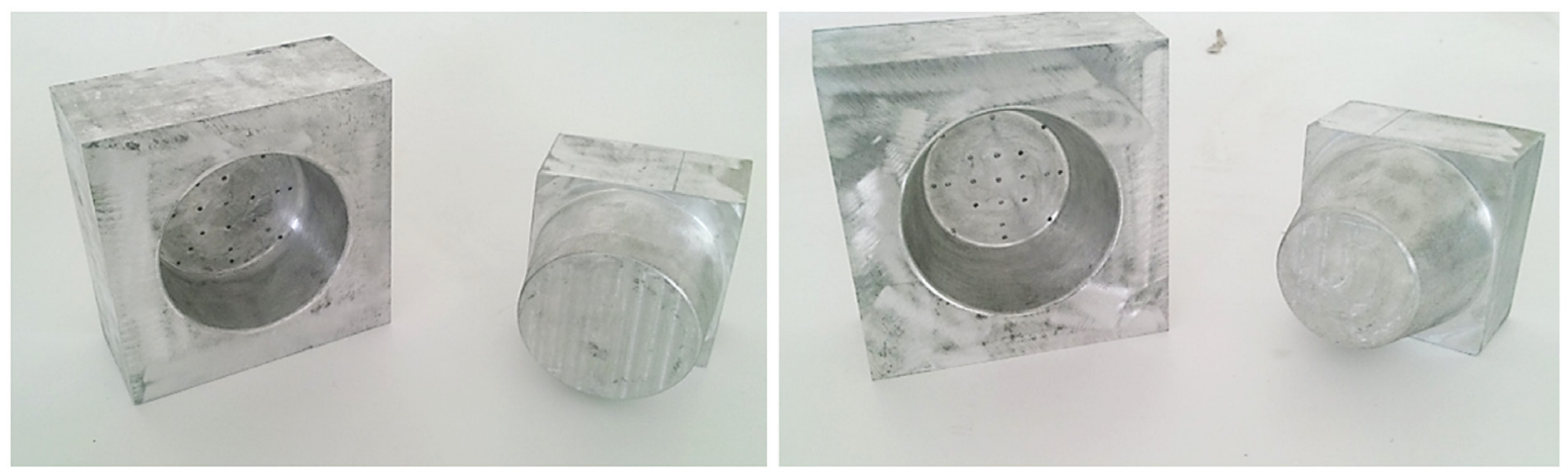

Fig. 4. Thermoforming Molds, cylindrical female and male mold, conical female and male mold, left to right respectively 


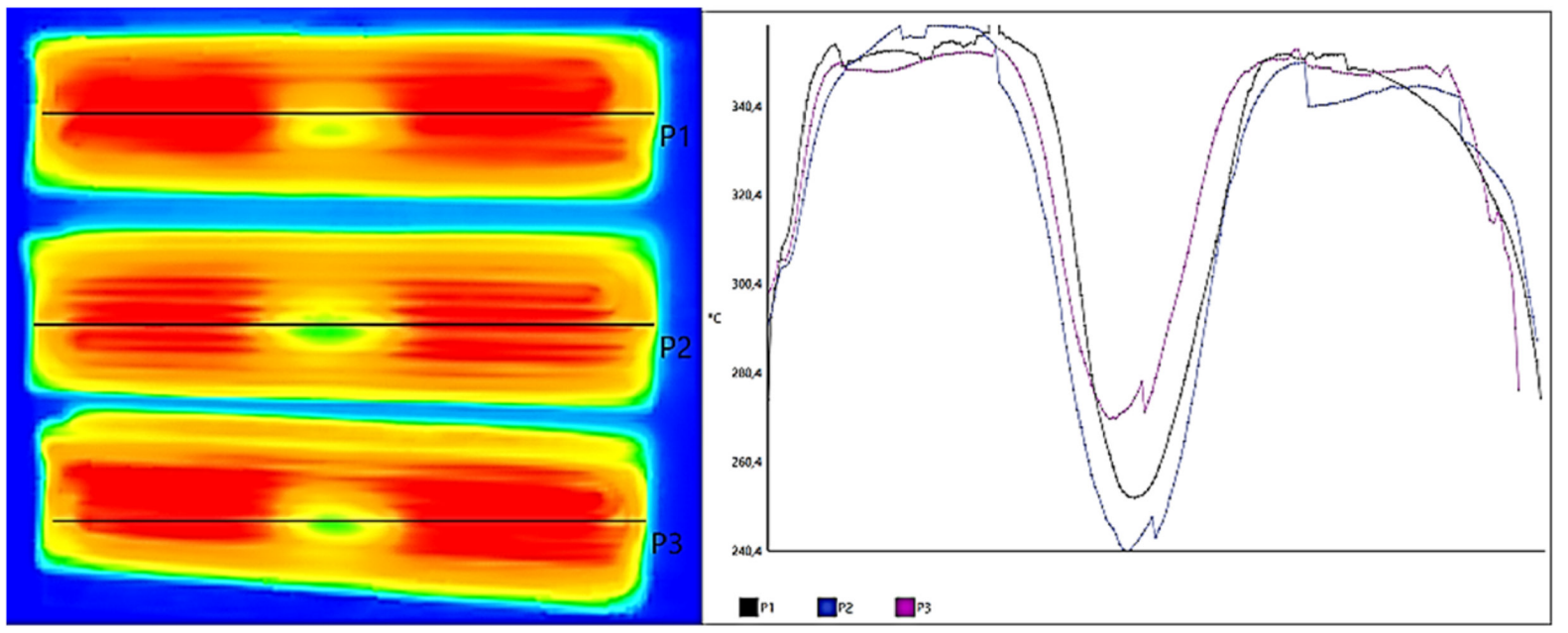

Fig. 5. Temperature distribution along the length of the heaters
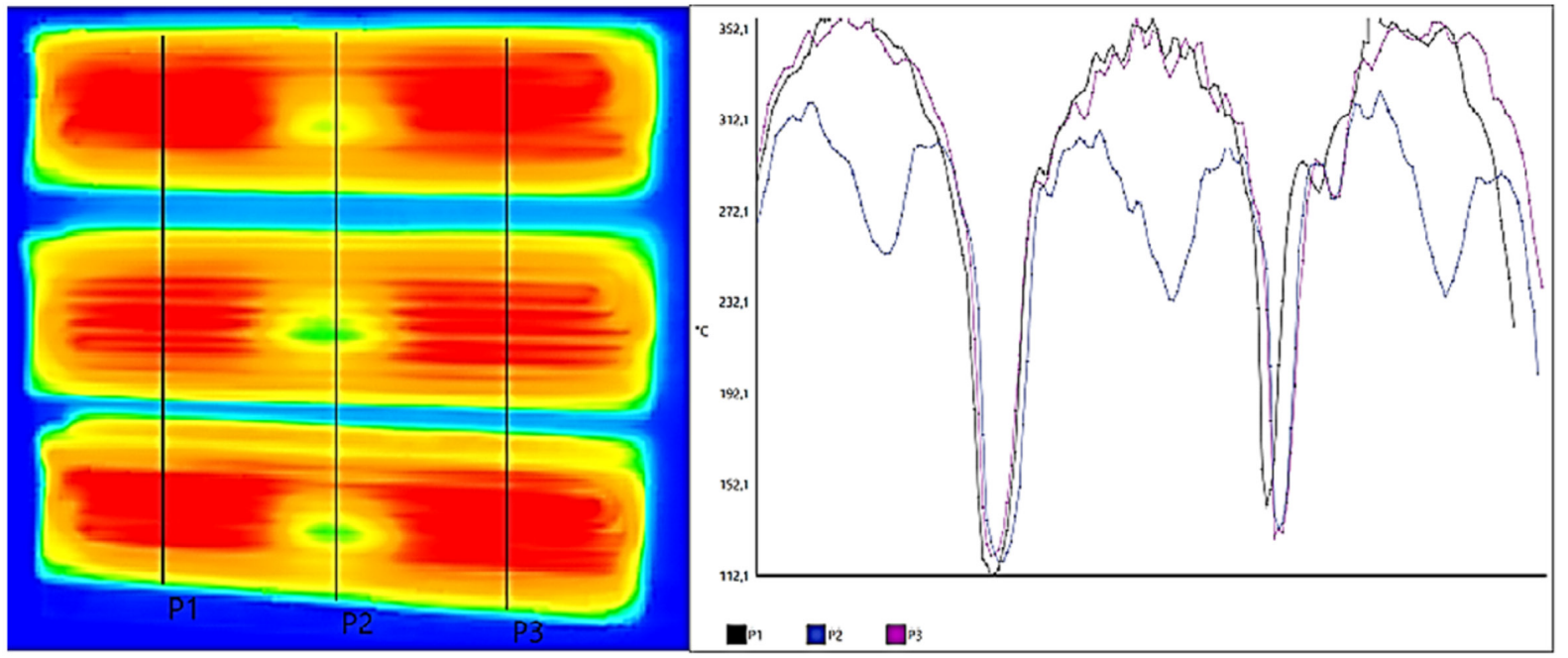

Fig. 6. Temperature distribution along the width of the heaters

ments have non-uniform temperature distribution. When the temperature has been adjusted to $350^{\circ} \mathrm{C}$ in the heater, the temperature has changed between $250^{\circ} \mathrm{C}$ and $350^{\circ} \mathrm{C}$ along the length and width of heater elements. However, temperature distribution on the heater is supposed to be the same at every point. Non-uniform temperature distribution on heater elements affects the temperature distribution on the sheet before forming.

As understood from Fig. 7 a heated sheet has non-uniform temperature distribution too. A thermal imaging camera showed that the temperature has approximately a $30^{\circ} \mathrm{C}$ variation range on the heated sheet after a heating time of 4 minutes. Normally, it is hard to thermoform a sheet which has a non-uniform temperature distribution in which temperature changes from $120^{\circ} \mathrm{C}$ to $150^{\circ} \mathrm{C}$.
However, PS which is an amorphous polymer, has a wide forming temperature window. That phenomenon makes PS possible to be thermoformed under $30^{\circ} \mathrm{C}$ temperature change.

One of the leading factors that affects the thickness distribution, is plug assist. In order to analyze its effects in detail, a male mold has been used in addition to female mold applications. Thickness distributions in different thermoformed products can be seen in Fig. 8, Fig. 9, and Fig. 10.

Thickness distributions obtained in hemispherical products and compared to each other. Thickness measurements have been performed on a profile that starts at the the center and bottom of the product, and the ends on the outer edge of the product. These measurements were taken at 


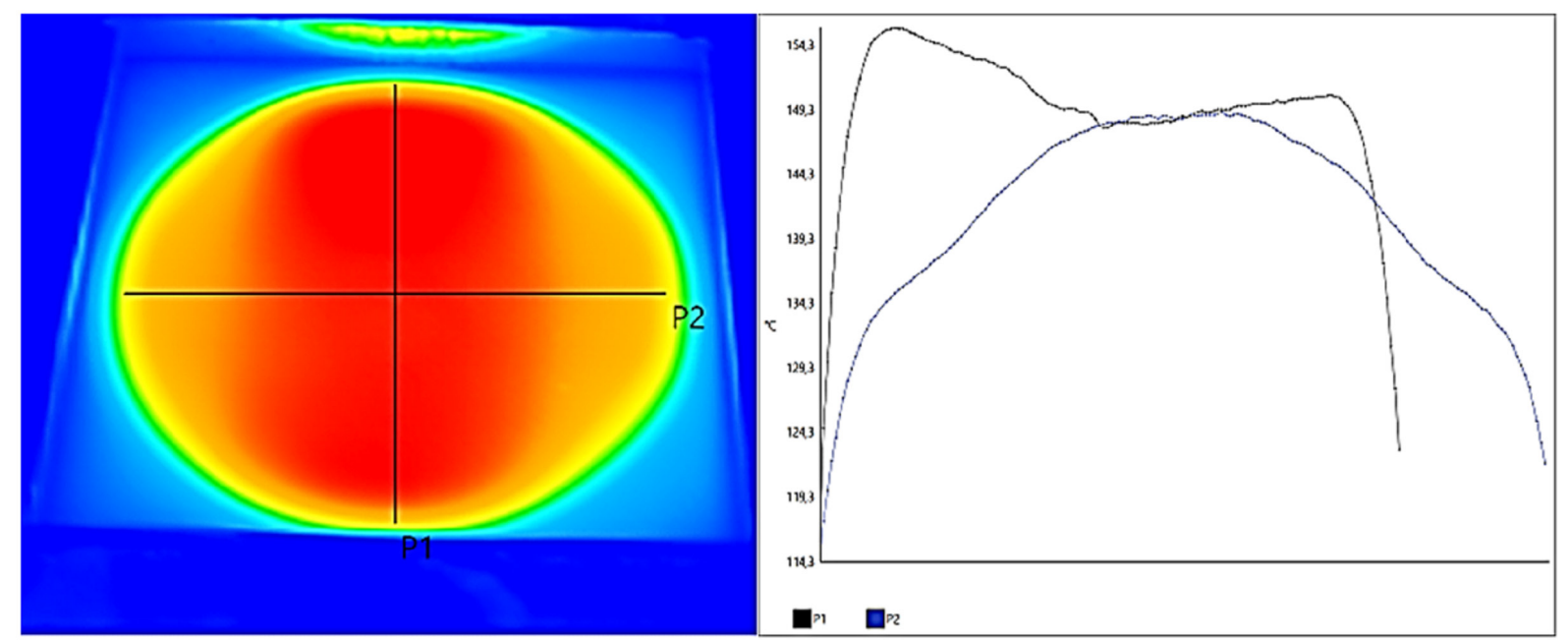

Fig. 7. Temperature distribution of the heated sheet before thermoforming

20 points in total. As a result of vacuum forming (female mold), thickness has an increasing trend outward from the center of the product. Minimum thickness was measured as $0.35 \mathrm{~mm}$ at the center of the bottom of the vacuum formed hemispherical product at point 1 . On the other side, min. thickness was measured as $0.79 \mathrm{~mm}$ at point 14 by plug-assisted thermoforming (male mold).

Minimum thickness was measured as 0.13 $\mathrm{mm}$ at point 6 by vacuum forming and $0.29 \mathrm{~mm}$ at point 6 by plug assisted forming in conical product. By vacuum forming, thickness distribution exhibits a constantly increasing trend. On the contrary, there is an unstable tendency for thickness distribution on the plug assisted thermoformed products. It is understood from the male mold applications that thickness firstly decreases then increases and decreases again on the sidewalls of the conical product (points 7-15). This is an indication of thickness accumulation on the sidewalls of the product. That phenomenon can be explained as a result of multiple causes. Before forming, the male mold touches the heated sheet firstly. Part of the heated sheet that touches the cold male mold, cools and hardens. That part of the sheet cannot deform anymore. Thickness accumulation on the sidewalls can be accepted as a result of this action.

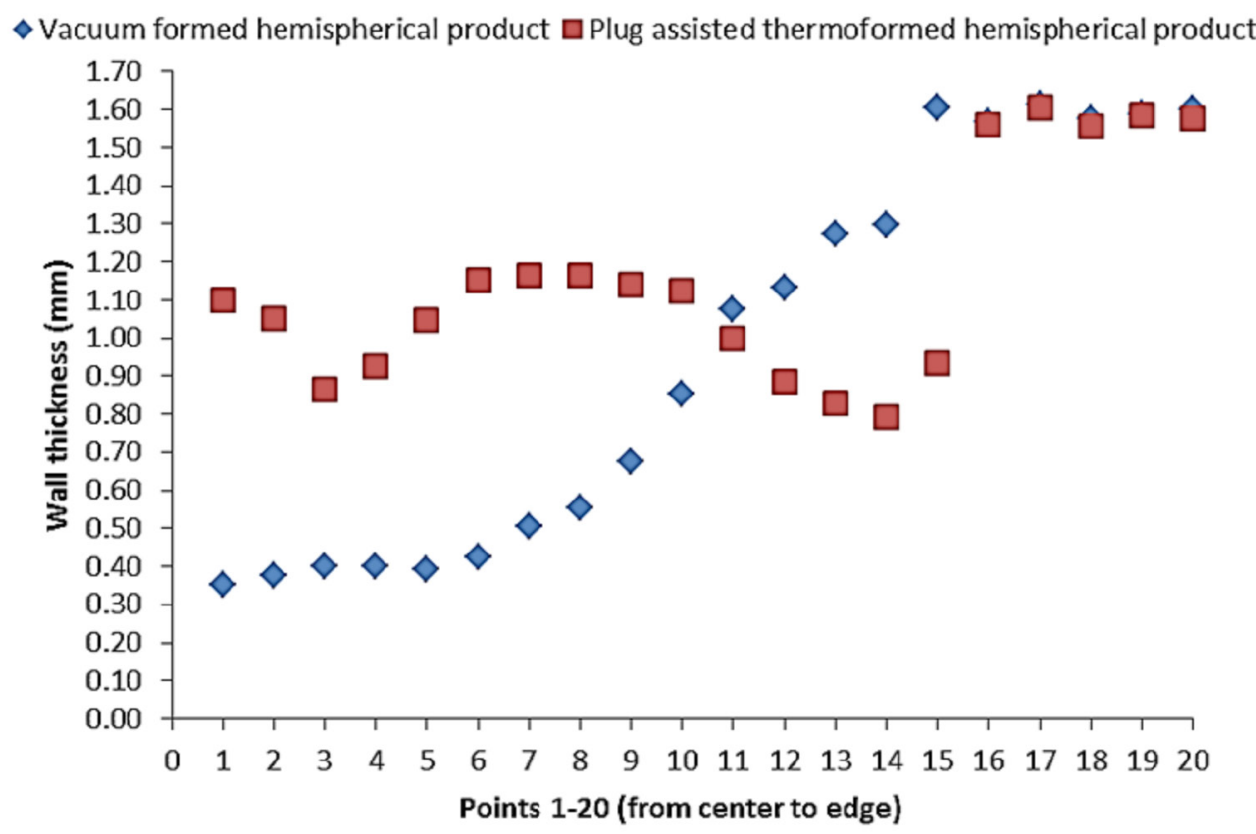

Fig. 8. Comparative thickness distribution in hemispherical product. 


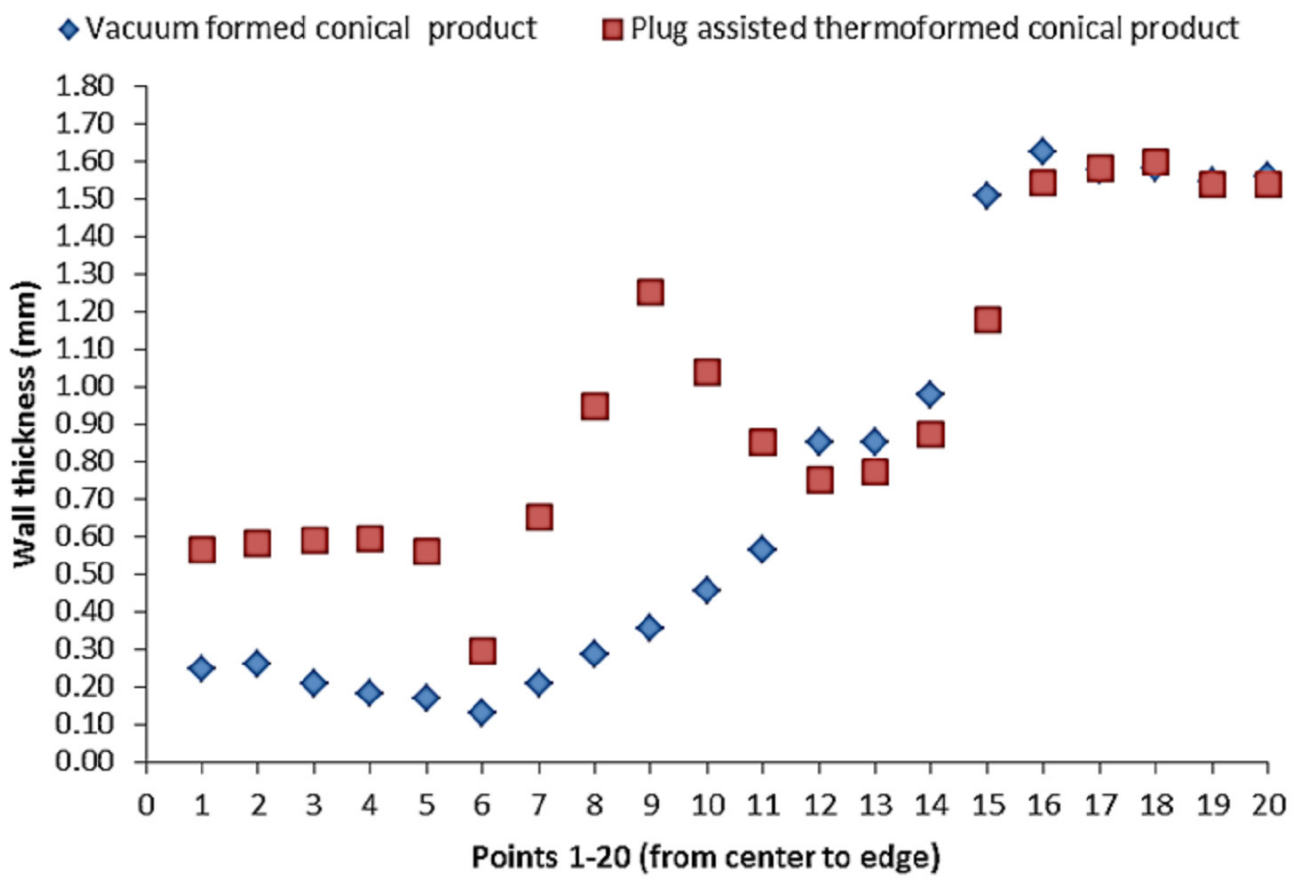

Fig. 9. Comparative thickness distribution in conical product

Minimum thickness was measured as 0.09 $\mathrm{mm}$ at point 7 in cylindrical products by vacuum forming. Point 7 is located on the radius at the bottom of the cylindrical product. Contrarily, minimum thickness value was measured as 0.24 $\mathrm{mm}$ at point 8 by plug assisted thermoforming. Point 8 is located near the radius where point 7 is located. Thickness distribution obtained from vacuum formed cylindrical samples has an increasing tendency from point 1 to point 15 , same as vacuum formed conical products. The decrease and increase in thickness from point 7 to point 15 in cylindrical products can be seen in conical products too.

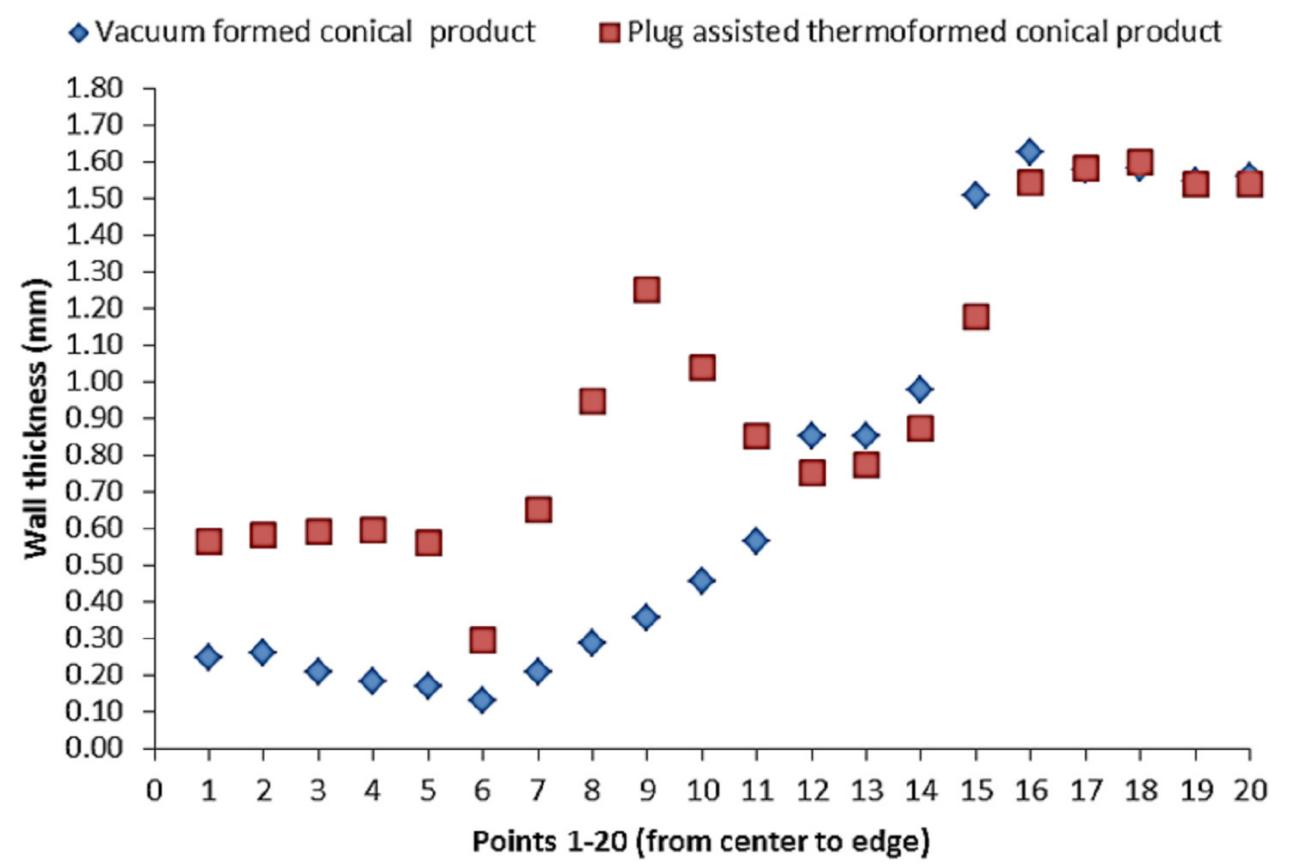

Fig. 10. Comparative thickness distribution in cylindrical product 


\section{CONCLUSIONS}

The effect of some process parameters on thickness distribution in thermoforming has been investigated in this study. Temperature distribution on heaters has been detected as an affecting parameter because the heaters have non-uniform temperature distribution. Nonuniform temperature distribution on heaters has caused non-uniform temperature distribution on heated sheet. Undesired temperature distribution on the heated sheet affected deformation and forming so affected thickness distribution too. But, the most important factor was determined as the type of forming process. Using plug assist increased the minimum thickness value in conical, cylindrical and hemispherical thermoformed products. In addition to this, using plug assist in thermoforming provided more uniform thickness distributions than negative (female mold) forming.

\section{Acknowledgements}

We would like to give our special thanks to Trakya University Engineering Faculty for the possibility of using Solidworks software.

\section{REFERENCES}

1. Farrington T., Coward T., Pearson G.O., Taylor R.L., Ear P., Winwood K.: An investigation into the relationship between thickness variations and manufacturing techniques of mouth guards. Dental Traumatology, 32, 1, 2016, 1-84.

2. Hosseini H., Berdyshev B.V., Zeinabad A.M.: A solution for warpage in polymeric products by plug-assisted thermoforming. European Polymer Journal, 42, 8, 2006, 1836-1843.

3. Klein P.W.: Fundamentals of Plastics Thermoforming, Morgan\&Claypool Publishers, USA, 2009.

4. Kojima I., Takeda T., Nakajima K., Narimatsu K., Konno M., Ozawa T., Ishigami K.: Thinning factors influence on custom-made mouth guards thermoforming. Dental Traumatology, 31, 2, 2015 , 103-112.

5. Lee R.E., Guo Y., Tamber H., Planeta M., Leung S.N.S.: Thermoforming of Polylactic Acid Foam Sheets: Crystallization Behaviors and Thermal Stability. Industrial \& Engineering Chemistry Research, 55, 3, 2016, 560-567.

6. Martin P.J., Duncan P.: The Role of Plug Design in Determining Wall Thickness Distribution in Thermoforming, POLYMER ENGINEERING AND SCIENCE, 47, 6, 2007, 804-813.

7. Takahashi M., Koide K., Satoh Y., Iwasaki S.: Heating methods for reducing unevenness softening of mouth guard sheets in vacuum-pressure formation. Dental Traumatology, 32, 4, 2016, 316-320.

8. Takahashi M., Koide K., Satoh Y., Iwasaki S.: Shape change in mouth guard sheets during thermoforming. Dental Traumatology, 32, 5, 2016, 379-384.

9. Tangpornprasert P., Virulsri C.: Factors Affecting Thickness of Prosthetic Socket in Thermoforming Fabrication. Applied Mechanics and Materials, 751, 2015, 159-163.

10. Throne J.L.: Thermoforming, Hanser Publishers, GERMANY, Munich, 1987.

11. Throne J.L.: Technology of Thermoforming, Hanser/Gardner Publications Inc., USA, 1996.

12. Throne J.L., Understanding Thermoforming, Hanser/Gardner Publications Inc., USA, 2008. 